\title{
Reflexão sobre a prática: o que e como reflete uma futura professora de matemática
}

\author{
Manuel Vara Pires ${ }^{\mathrm{a}}$ \\ ${ }^{a}$ Centro de Investigação em Educação Básica, Instituto Politécnico de Bragança, Portugal, \\ mvp@ipb.pt.
}

\section{Resumo}

Esta comunicação apresenta aspetos do conteúdo das reflexões escritas por uma futura professora sobre uma experiência de ensino e aprendizagem em sala de aula. Esta experiência foi desenvolvida numa turma de matemática com dezanove alunos do $6 .^{\circ}$ ano de escolaridade, abordando uma unidade de ensino relacionada com tópicos estatísticos. A futura professora, assumindo características de ensino exploratório e de reflexão sobre a prática, propôs aos seus alunos um trabalho estatístico de natureza mais investigativa, que proporcionou uma organização e tratamento de dados apelando a diferentes modos de registo e representação da informação recolhida, como a construção de gráficos usando materiais de desenho ou um suporte digital. $O$ estudo sobre as reflexões escritas foi orientado para a identificação do conteúdo em que incidiram as apreciações da futura professora. Começando com uma leitura flutuante do relato da experiência, foi evoluindo para leituras mais precisas e organizadas dos registos escritos, fazendo emergir sobre o que a futura professora refletia, que permitissem categorizar o respetivo conteúdo. A futura professora concentrou as suas reflexões escritas em diversas dimensões relevantes da prática letiva, revelando, por exemplo, as suas preocupações com a criação de contextos de aprendizagem estimulantes para os seus alunos, a relevância das práticas de avaliação dos desempenhos dos seus alunos, a diversificação dos modos de trabalho dos seus alunos, a importância do desenvolvimento de atitudes positivas relativamente à matemática ou a projeção do trabalho futuro a desenvolver.

Palavras-chave: educação básica, reflexão sobre a prática, reflexão escrita. 


\section{Contexto do estudo}

O estudo, que se apresenta neste texto, está contextualizado no Relatório Final de Estágio (RFE) elaborado e defendido publicamente por uma futura professora (Teresa, nome fíctício) na conclusão do Mestrado em Ensino do $1 .^{\circ}$ e do 2. ${ }^{\circ}$ Ciclo do Ensino Básico na Escola Superior de Educação de Bragança, concretizando o trabalho realizado na Prática de Ensino Supervisionada (PES) e relativo ao estágio profissional para a docência. O regulamento da instituição, que orienta a elaboração e redação do RFE, regista que os futuros professores devem "apresentar, de forma contextualizada, experiências de ensino e aprendizagem realizadas ao longo do estágio, abrangendo os vários níveis de educação ou ciclos de ensino e disciplinas do domínio de habilitação, e reflexão crítica sobre as mesmas. Esta reflexão deve ser sustentada na literatura científica, pedagógica e investigativa de referência e em dados da prática”. É, assim, visível a assunção do papel central que a reflexão ocupa na construção e desenvolvimento do conhecimento profissional, acompanhando as evidências da relevância dos processos reflexivos no pensamento e nas práticas de um professor largamente documentadas na literatura (Kwon \& Orrill, 2015; Martins \& Santos, 2012; Schön, 1983).

No seu relatório, Teresa apresentou e refletiu sobre experiências de ensino e aprendizagem realizadas nos dois ciclos de ensino e nas diversas disciplinas de docência, que foram enquadradas pelo tema integrador "recursos para a aula" que trabalhou ao longo da PES. Este texto centra-se na análise das reflexões escritas que a futura professora produziu sobre uma experiência de ensino e aprendizagem desenvolvida numa aula de matemática no tema "Organização e tratamento de dados (OTD)" em que os alunos recorreram ao Excel.

\section{Enquadramento teórico}

Embora possam ser associadas perspetivas e características diversas ao conceito de reflexão, entendemo-la como "um processo mental de tentar estruturar ou reestruturar uma experiência, um problema, ou o conhecimento existente, conduzindo à compreensão destes e constituindo-se como um processo contínuo de análise e refinamento da prática, em que o carácter recursivo e a natureza cíclica definem sumariamente a forma como se processa" (Martins, Pires, \& Sousa, 2017, p. 411).

$\mathrm{Na}$ literatura em educação, há um grande consenso no reconhecimento da reflexão como um processo essencial para interpretar, compreender e dar sentido à atividade profissional de um professor (Eynon, 2009; Korthagen, 2012; Kwon \& Orrill, 2015; Martins \& Santos, 
2012; Sellars, 2014), permitindo-lhe analisar as suas próprias práticas e atuações. Mas, como realça Korthagen (2012), “a reflexão sistemática e eficaz” é um processo que requer aprendizagem no sentido de "trazer os aspetos inconscientes do ensino para o nível da consciência" (p. 155).

Schön (1983) introduz três tipos de reflexão associados ao conhecimento em ação: a reflexão na ação, reflexão sobre a ação e a reflexão sobre a reflexão na ação. A reflexão na ação é um processo de diálogo do sujeito com uma situação problemática, sem a interromper, através do qual o professor aprende a partir da análise da sua própria atuação. A reflexão sobre a ação e a reflexão sobre a reflexão na ação correspondem a processos de análise que o professor realiza a posteriori sobre as características e o decurso da sua própria ação, relacionando o conhecimento na ação e a reflexão na ação com a situação problemática e o seu contexto. Todos estes processos, interligados e complementares uns dos outros, ajudam o professor a enfrentar as situações divergentes da prática, proporcionando-lhe uma intervenção prática racional.

É importante atender ao conteúdo da reflexão (Meireles (2005), que não pode nem deve ser relegado para um segundo plano. Igualmente importante é o papel da escrita no desenvolvimento das práticas reflexivas, potenciando o seu aprofundamento, pois "ao escrever, o professor toma consciência de seu próprio processo de aprendizagem" (Passos, Nacarato, Fiorentini, Miskulin, Grando, Gama, Megid, Freitas, \& Melo, 2006, p. 202).

\section{Enquadramento metodológico}

O estudo segue uma abordagem de natureza qualitativa e interpretativa (Amado, 2014; Bogdan \& Biklen, 1994), procurando compreender o que é único e particular para a futura professora na interpretação e reflexão que faz das diferentes experiências que foi vivendo e que significados lhes atribue.

A experiência de ensino e aprendizagem apresentada no relatório final de estágio assume características de investigação-ação e de investigação sobre a prática (Ponte, 2002). A futura professora suportou a escrita da experiência, realizada com os seus dezanove alunos de uma turma de matemática do $6 .^{\circ}$ ano de escolaridade, em notas de campo registadas num diário de bordo construído ao longo do estágio profissional, na observação direta da atividade dos alunos em sala de aula e na análise das respetivas produções e opiniões. A reflexão sobre a prática foi perspetivada para a compreensão da experiência de ensino e aprendizagem, dando-lhe consistência e coerência. 
A análise das reflexões escritas pela futura professora foi orientada para a identificação do conteúdo em que incidiram as referências reflexivas apresentadas na experiência de ensino e aprendizagem. O primeiro contacto com estas referências reflexivas foi feito através de uma leitura flutuante (Amado, 2014) da experiência, que foi evoluindo para leituras cada vez mais sistematizadas do material escrito, procurando fazer emergir sobre o que a futura professora refletia e que aspetos de sala de aula mais valorizava

\section{A experiência de ensino e aprendizagem}

A experiência corresponde ao final da unidade de ensino "Organização e tratamento de dados" em que foi valorizada a investigação estatística nas suas diferentes dimensões: (i) definição de uma questão a investigar; (ii) seleção dos tipos de variável a tratar e recolha de dados; (iii) organização e tratamento da informação recolhida; e (iv) apresentação da informação e estabelecimento de conclusões. Nesta aula os alunos trabalharam os tópicos "tabelas de frequências absolutas e relativas, gráficos de barras, diagramas circulares" e o objetivo "construir e interpretar tabelas de frequências absolutas e relativas, gráficos de barras, diagramas circulares" (Ministério da Educação, 2007, p. 43), recorrendo a diferentes formas de representação da informação. Teresa justificou as opções feitas, afirmando que “os alunos já tinham conhecimento das possíveis hipóteses de representação, tendo clarificado vantagens ou desvantagens de cada possibilidade. Na aula de conclusão do tema optei, então, por proporcionar aos alunos uma aula que recorresse a um meio distinto do habitual, em que fizessem a representação de dois gráficos [barras, circular] em Excel".

\section{Reflexões sobre a experiência de ensino e aprendizagem}

Nas suas reflexões, Teresa registou dimensões muito relevantes para uma melhor compreensão da dinâmica da sala de aula e dos papéis desempenhados pelos intervenientes, diversificando o respetivo conteúdo. Teresa refletiu sobre (i) aspetos de âmbito global, como os contextos de aprendizagem, a organização da sala de aula, a importância da OTD, das TIC ou as atitudes face à matemática; (ii) aspetos mais relacionados com o papel dos alunos, como as suas dificuldades, modos de trabalho, produções que realizam ou a resolução de tarefas de natureza mais investigativa; e (iii) aspetos mais relacionados com o seu papel de professora, como as práticas de avaliação dos desempenhos, a reformulação de estratégias em ação ou implicações no trabalho futuro. Apresentam-se cinco situações que realçam e evidenciam aspetos do conteúdo das reflexões escritas por Teresa no seu RFE. 


\section{Situação 1: atitudes face à matemática}

Há então que focar o objetivo no sentido de influenciar os alunos na forma como eles vêem e encaram a matemática o que, a longo prazo, se torna um fator fundamental à sua compreensão e empenhamento. Para isso, é importante que o professor, ele próprio, entenda a matemática como "dinâmica, que engloba o estudo de padrões, [em que] as interações serão muito abertas e incluirão indubitavelmente explorações, discussões e expressões escritas dos processos de pensamento dos alunos e conclusões" (Matos \& Serrazina, 1996, p. 167). Como era bem evidente a ideia dos alunos de que a disciplina de matemática era, essencialmente, um "conjunto de procedimentos ou algoritmos a seguir" (p. 167), não proporcionando um crescimento face à matemática, selecionei uma tarefa que se afastasse dessa mesmo ideia e permitisse as explorações próprias ou a partilha de ideias e argumentos. (Teresa)

As atitudes que alunos e professores vão desenvolvendo sobre a matemática revelam-se uma preocupação para Teresa, dado que podem influenciar, decisivamente, o ensino e a aprendizagem desta disciplina. Apoia a sua reflexão em literatura de referência, destacando a natureza mais estática ou mais dinâmica da maneira como se encara e vê a matemática. Partindo da perceção que tem das ideias dos seus alunos baseadas em perspetivas mais estáticas, realça a visão da matemática como um saber dinâmico ligando-o à exploração de situações e à partilha de opiniões. Neste sentido, prepara e propõe aos seus alunos uma tarefa matemática que lhes permita um envolvimento mais ativo e reforce as possibilidades de exploração e discussão dos diferentes pontos de vista.

\section{Situação 2: modos de trabalho dos alunos}

Numa primeira fase, a ideia que melhor me convencia seria o trabalho individual (...). Contudo, refletindo melhor acerca deste fator, vejo vantagens e concordo que a interação entre pares pode contribuir para o desenvolvimento pessoal do aluno, embora acrescentem novas exigências para o professor. Em trabalhos de grupo, existe uma maior preocupação por parte do professor, visto que todos os grupos apresentaram ritmos de trabalho bastante diferenciados, "tornando por vezes difícil encontrar um momento apropriado para se fazer uma discussão geral ao nível de toda a turma" (Abrantes, Leal, Teixeira \& Veloso, 1997, p. 61), o que me exigiu uma mobilidade constante, um acompanhamento mais pormenorizado e individualizado, a maior parte das vezes para esclarecer pontos que já tinham sido referidos numa primeira explicação coletiva. Esta circunstância deve-se ao próprio facto do trabalho ser realizado em grupo, com questões não relacionadas com o trabalho em si que, desviando a atenção do aluno, o desconcentram do que realmente é importante. Mas a interação entre pares (...) promove a autoestima dos alunos, demonstrando-lhes que os seus argumentos e raciocínios são escutados e respeitados, aprendendo a modificar as estratégias consoante a necessidade e defendendo os pontos de vista. (Teresa)

A organização e gestão do trabalho dos alunos em sala de aula merece um destaque especial por parte de Teresa e, nesta transcrição, é visível a influência da reflexão na alteração das suas opções docentes, passando de uma proposta de trabalho individual para um trabalho em pares. Refletir sobre o modo mais adequado como os alunos devem resolver uma tarefa, permite a Teresa destacar o papel importante das interações na sala de aula e ter consciência que diferentes modos de organização exigem, ao professor, diferentes formas de gerir o 
trabalho letivo. Mais uma vez, as suas reflexões suportam-se em bibliografia de referência, colocando em evidência que refletir é sustentar e dar mais sentido às opiniões que se vão formando e, por isso, é sempre um processo intencional.

\section{Situação 3: tarefas de natureza mais investigativa}

Seria de todo o meu agrado proporcionar aos alunos uma investigação livre, [pois] oferecer aos alunos uma abordagem investigativa "envolve uma mudança no poder do professor que deixa de ter controlo sobre as respostas" (Abrantes, Leal \& Ponte, 1996, p. 31). [Também] ocorre no aluno uma transformação, dando-lhe a oportunidade de "dominar os conteúdos a tratar, as metodologias a utilizar e as soluções a aplicar” (p. 31), o que altera os processos de verificação do professor (...). No entanto, em grande parte devido à gestão curricular do tempo destinado ao tema, a opção não foi por um trabalho de investigação "integral" mas apenas por alguns aspetos importantes do trabalho investigativo. [Constato que] existe alguma rejeição por parte dos professores relativa às investigações, sendo vistas como uma perda de tempo, ocupando o lugar do "trabalho duro" que deve ser dedicado à matemática (p. 32). No entanto, torna-se fundamental aumentar o sentido de autonomia dos alunos, recusando a ideia de que o indivíduo apenas deve assimilar a informação mecanicamente. (...) Após uma reflexão mais aprofundada sobre esta opção, penso que é necessária uma aprendizagem mais completa que permita lidar com os erros tornando os alunos mais capazes de fazer novas reformulações e experimentações. (Teresa)

Teresa reflete sobre o trabalho matemático a desenvolver pelos seus alunos, em especial o trabalho de natureza mais aberta e exploratório, concretizado nas tarefas que resolvem em sala de aula. Ao pensar em propor uma investigação "livre", a futura professora pretende proporcionar, aos alunos, momentos de uma maior autonomia na procura de caminhos e de soluções. No entanto, motivada por restrições de tempo, alarga a reflexão sobre a integração deste tipo de tarefas na aula de matemática relacionando-a com implicações na gestão e desenvolvimento curriculares e nos papéis desempenhados por alunos e pelo professor, nomeadamente, na validação de processos e resultados.

A atividade experienciada evidencia sobre os alunos uma recetividade e uma produtividade francamente positiva (...) tornando o aluno num individuo participante, crítico e argumentativo. Este tipo de atividades permite mudar a imagem "tradicional" da matemática que se enraíza nos alunos. Procura-se a mudança na forma como vêem a matemática, apelando à substituição de estratégias transmissivas por estratégias mais ativas, diversificando os instrumentos utilizados e evoluindo para processos que permitam partilhar e acrescentar novas informações. (Teresa)

Refletindo após a realização da tarefa, Teresa reconhece o bom envolvimento e desempenho dos alunos, que assumem papéis mais ativos nas suas aprendizagens, retomando a relevância do desenvolvimento de atitudes positivas face à matemática. Para Teresa, este maior protagonismo dos alunos na aula também tem consequências nas suas práticas de ensino, que devem ser mais orientadas para um ensino do tipo exploratório em contraponto a um ensino do tipo direto e essencialmente transmissivo. 


\section{Situação 4: avaliação dos desempenhos dos alunos}

Todos os trabalhos foram identificados e (...) recolhidos, em suporte digital, para uma posterior avaliação. É necessário manter práticas de avaliação em todas as aulas e, neste caso, não se tratou de uma exceção. Esta avaliação esteve mais direcionada para aspetos do comportamento, da responsabilidade e da capacidade de trabalhar em grupo, enfatizando o esforço do próprio aluno. Também dei importância ao produto final das produções dos alunos, visto que informa se os passos seguidos durante o processo foram os corretos. Não os avaliei quantitativamente dado que a intenção principal foi proporcionar o primeiro contacto com diferentes instrumentos de cálculo, o que originou um auxílio bastante forte por parte de todos professores e, portanto, as produções foram muito apoiadas. Em termos gerais, os resultados finais também não tiveram grandes discrepâncias, não se evidenciando os diferentes níveis [habituais] de aprendizagem dos alunos. Aliás, se alguma distinção se pode fazer, os alunos considerados com desempenho mais fraco apresentaram gráficos mais "requintados" em termos estéticos. No final da aula pedi aos alunos que identificassem as principais dificuldades sentidas na utilização (...) do Excel, assim como a utilidade e os benefícios da utilização da folha de cálculo na organização e tratamento de dados. (Teresa)

As práticas de avaliação são muito valorizadas por Teresa, que as integra nas rotinas da sala de aula. Realça a sua dimensão formativa, refletindo quer sobre as atitudes ou os comportamentos e os processos que os alunos desenvolvem quer sobre os produtos que concretizam. Diversifica, igualmente, as fontes de recolha da informação, dando importância às opiniões e pontos de vista dos alunos, bem como às suas produções escritas.

\section{Situação 5: implicações para o trabalho futuro}

Se tivesse mais tempo, seria possivelmente mais significativo fornecer aos alunos não a ficha de trabalho mas um guião com os passos a seguir para a realização da atividade. Desta forma, cada aluno sentir-se-ia mais responsável (e mais autónomo) para concretizar as tarefas, visto que não teria que esperar pelos outros grupos para avançar nos procedimentos da atividade. Esta atuação favorece a concentração no trabalho, afastando momentos de dispersão, e o desenvolvimento da comunicação com o colega do par ou com o professor. [...] Embora o tempo destinado para a unidade de ensino não o tenha permitido, teria sido uma boa opção propor aos alunos a produção de um relatório escrito sobre o trabalho realizado. A atividade teria proporcionado o desenvolvimento da capacidade de interpretação e consequente comunicação matemática, através de uma análise escrita e individual das conclusões retiradas dos gráficos produzidos. (Teresa)

Por vezes, nas suas reflexões escritas, Teresa tenta colocar e fundamentar alternativas à opção seguida, especialmente quando a considera que não foi muito bem sucedida. Analisando a preparação e a concretização da tarefa, a futura professora pensa que teria sido mais útil para os seus alunos ter dado melhores orientações para o trabalho a realizar em pares e ter optado por solicitar a produção de um relatório escrito, pois permitir-lhes-ia melhores oportunidades para interpretar e comunicar as respetivas opiniões e produções. 


\section{A concluir: projeção da vida profissional}

As suas considerações escritas sobre o trabalho que ia realizando evidenciam características associadas à reflexão, como sejam a estruturação, a intencionalidade, a continuidade, a interpretação ou a análise (Eynon, 2009; Schön, 1983). Teresa, enquanto futura professora, revela uma grande preocupação com os processos reflexivos e, através deles, procura compreender e dar sentido às suas práticas de ensino (Korthagen, 2012; Martins \& Santos, 2012). Esta valorização, aliada à prática da reflexão, permite-lhe discutir e procurar outras soluções ou outros caminhos para resolver situações colocadas na sua atividade letiva, estar mais atenta à complexidade dos ambientes de aprendizagem dos seus alunos, ter uma visão mais articulada e global das suas práticas de ensino e reconhecer a importância da integração da reflexão na vida profissional (Kwon \& Orrill, 2015; Sellars, 2014).

A concluir, como afirma Teresa na projeção da sua atividade profissional futura, todo o trabalho realizado "consciencializou-me para o facto de existir uma real necessidade do (futuro) professor refletir sobre as suas práticas profissionais e de que este facto deverá fazer parte do processo contínuo do que é realmente ser professor". É, então, fundamental "adotar, ao longo da nossa carreira, uma postura flexível, autocrítica, reflexiva e autoavaliativa, tendo a plena consciência de que em todo o processo educativo os alunos aprendem com os professores e os professores aprendem com os alunos. Penso que este será o melhor caminho a seguir para nos tornarmos cada vez melhores profissionais".

\section{Referências}

Amado, J. (Coord.) (2014). Manual de investigação qualitativa em educação. Coimbra: Universidade de Coimbra.

Bogdan, R., \& Biklen, S. (1994). Investigação qualitativa em educação. Porto: Porto Editora.

Eynon, B. (2009). Introduction. Transit, 4, v-xviii.

Korthagen, F. (2012). A prática, a teoria e a pessoa na formação de professores. Educação, Sociedade \& Culturas, 36, 141-158.

Kwon, N. Y., \& Orrill, C. (2015). Reflection as professional knowledge for mathematics teachers. Journal of Korean Society of Mathematical Education, 19(1), 1-17.

Martins, C., Pires, M. V., \& Sousa, J. (2017). Reflexão escrita sobre experiências de ensino e aprendizagem: articulação conteúdo-profundidade. In M. V. Pires et al. (Eds.), Livro de atas do II Encontro internacional de formação na docência, INCTE 2017 (pp. 411-418). Bragança, Portugal: Instituto Politécnico de Bragança. http://hdl.handle.net/10198/15415 
Martins, C., \& Santos, L. (2012). O Programa de Formação Contínua em Matemática como contexto favorável para o desenvolvimento da capacidade de reflexão de professores do $10^{\circ}$ ciclo. Quadrante, XXI(1), 95-119.

Meireles, M. (2005). Formação inicial de professores: a reflexão dos professores e a pedagogia da escrita. In I. Alarcão (Orgs.), Supervisão: investigações em contexto educativo (pp. 217-232). Ponta Delgada: Universidade de Aveiro \& DGE, Governo Regional dos Açores.

Ministério da Educação. (2007). Programa de matemática do ensino básico. Lisboa: ME.

Passos, C. et al. (2006). Desenvolvimento profissional do professor que ensina matemática: uma meta-análise de estudos brasileiros. Quadrante, XV(1-2), 193-219.

Ponte, J. P. (2002). Investigar a nossa própria prática. In GTI (Org.), Refletir e investigar sobre a prática profissional (pp. 5-28). Lisboa: Associação de Professores de Matemática.

Schön, D. (1983). The reflective practitioner: how professionals think in action. New York: Basic Books.

Sellars, M. (2014). Reflective practice for teachers. London: Sage. 